\title{
MOOD LIGHTING USING DAYLIGHT IN GREEN BUILDINGS
}

\author{
Shivsharan.M \\ Department of Mechanical \\ Rajalakshmi engineering college \\ Chennai, Tamilnadu, India
}

\author{
Shyam Sundar.B.T. \\ Department of Mechanical \\ Rajalakshmi engineering college \\ Chennai, Tamilnadu, India
}

\begin{abstract}
The use of daylighting technique signifies a solution for energy-efficient lighting in the interiors of a building. Thus, this paper provides a conceptual technique that courses daylight into the building through a mirror tube. Although daylighting illumination is energy efficient and has many health benefits, it also potentially causes heat transmission and glare which impacts people's visual comfort. To resolve the issue, this paper also focuses on proposing a technique to control the intensity of light transmitting into the room and also to change the colour of the light which falls into the concept called "mood lighting"
\end{abstract}

Keywords - Daylighting, mirror tube, the intensity of light, mood lighting.

\section{INTRODUCTION}

Since the first dawn, humans depended on the sun as the main source of light and heat. With its vast spectrum varying from ultraviolet to near-infrared rays, sparkles upon the earth's surface as a collocated beam, throughout the day, every day.

But in this modern life, we must spend $80 \%$ of our time indoors (1), which leads to detaching ourselves from the advantages of natural lighting. Hence, we humans had to use various artificial lightings to imitate the benefits of natural lighting. Yet, continuous researches have shown that the performance, productivity of humans are comparatively better when they work with the effect of natural lighting. Some health and wellness benefits when more natural light is allowed into the building are, a better worker and visitor satisfaction, improved cognitive function, finer Circadian rhythms (2).

Hence, an evident solution for this issue is to use the concept "Daylighting". Daylighting is a practice in which the natural sunlight is admitted into a building to reduce artificial lighting such as electric lighting. It is one of the main practice which is predominantly being applied in green buildings. The most basic way of applying this concept is by fenestration of windows accordingly, through which the sunlight courses into the building, which can provide effective internal lighting (3). Besides this technique, there are numerous other passive daylighting techniques/strategies which are incorporated in residences, workspaces \& industries to bring in daylight. Which include the introduction of Atriums, Clerestory windows, Light shelves, solar tubes and usage of smart glasses in windows. Each technique has its distinctiveness. This paper mainly focuses on the Solar tube technique.

The next generation of lighting banks on material innovations and their advancements. Taking that into consideration this paper also targets to bring about the use of innovative materials to control the intensity and the colour of the light coursing into space.

\section{MoOD LIGHTING}

Just like how weather affects the mood of a person, numerous researches state that the intensity and the colour of the light inside a room influence the frame of mind of a person. The lighting which sets up a particular

atmosphere inside space is termed "Mood lighting". This technique often uses soft colours to enhances the ambience within an area. This is because our body responds to the psychological effects of colours, which in turn changes our $\operatorname{mood}(4)$.

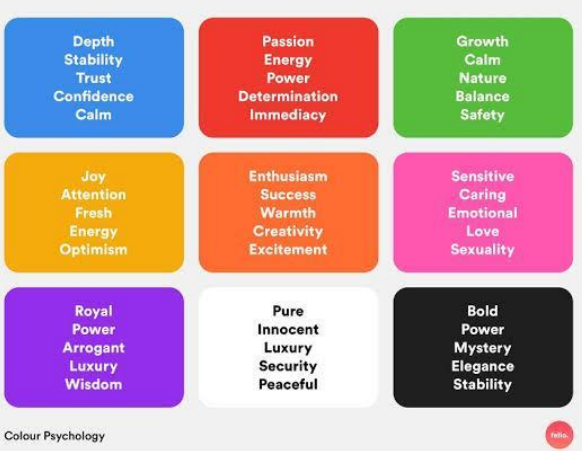

Fig 1. Universally followed colour psychology (5)

As the above-stated line mentions about the mood changing concept inflnce humans, it depends on a notion called colour psychology. Colour psychology varies according to the specific age, gender and culture. But these are the generally used colours in this notion. This research is based on this "mood lighting". 


\section{CONCEPTUAL SETUP \& COMPONENTS USED:}

This section provides a brief description of the components in the newly proposed concept using the solar tube for mood lighting.

\section{Heliostat collector:}

A heliostat collector is a simple large/ small mirror that helps in guiding the sunlight or daylight into the mirror tube. For the conceptual idea used in this paper, the heliostat is made of 2-3 slightly concaved mirrors angling the rays towards a focal point. The optimum area of the heliostat used in the setup depends on the receiving end's area (mirror tube). The use of this Solar concentrating solar power system (CSP), compared to others is that it is available in larger areas which helps in reflecting more sunlight into the mirror tube (i.e., a heliostat reflects approximately its area in sun energy - one kilowatt per sq. meter) (6).

\section{Solar tracker:}

A solar tracker typically adjusts its face of the reflective surface such that it aligns with the sun always as it moves across the sky. It uses astronomical theory to calculate the speed, elevation, compass bearing, direction of the sun from the collector. For the concept proposed in this paper, dual-axis tracking (up/down and left/right) would be preferred due to its reliability, optimised energy collection and flexibility. Trackers are controlled by computers. Usually, the mirrors are rotated at a rate of $1 / 2$ or $1 / 3^{\text {rd }}$ the motion of the sun (depends on the region).

\section{Mirror tube:}
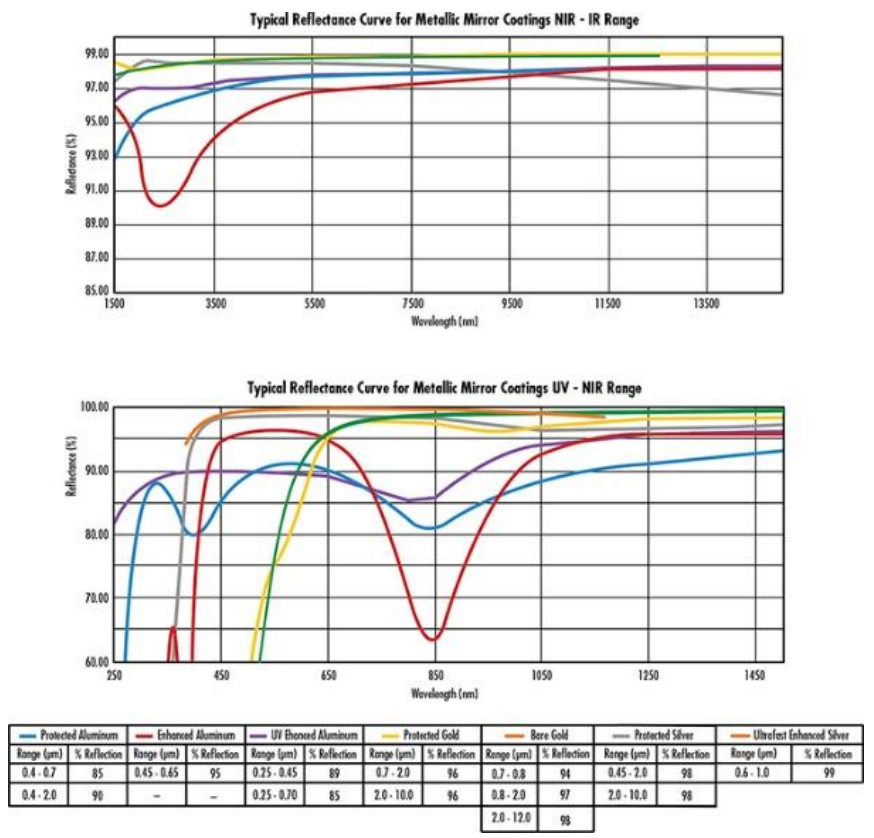

Fig 2. Materials and their reflectance (7)

It is a flexible reflective tube that allows natural light into the room without heating the room or letting harmful UV rays.From the data above it is found that using protected silver or gold coating (yellow and silver colour in the diagram) would be the best option because both the coatings have high reflectance $(96 \%<$ reflectivity) and can reflect rays in a vast range of wavelength (varying from 200nm to nearly $1400 \mathrm{~nm}$ ). Protective silver metallic coatings are used in broadband applications, hence considering the above point it should reflect light that spans in multiple spectral regions. Also protected silver can transmit an energy density of about 0.5 $\mathrm{J} / \mathrm{cm}^{2} @ 532 \mathrm{~nm} \& 1064 \mathrm{~nm}$, whereas protected gold can transmit about $0.8 \mathrm{~J} / \mathrm{cm}^{2} @ 1064 \mathrm{~nm}$, which are relatively higher as compared to other metallic-coated materials.

\section{Tinted glass:}

A type of plain glass that is treated with film or coating, which helps in diminishing the light transmitting through it. These small additions as coating or films, colour the glasses (usually bronze, green, blue or grey) but do not affect the principal properties of the glass besides, it only changes the solar energy transmission through it. In addition, these glasses also help in absorbing UV radiation.

\begin{tabular}{|c|c|c|c|}
\hline & $\begin{array}{c}\text { VLT } \\
\text { VISIELELGHT } \\
\text { TRANSMISSION }\end{array}$ & $\begin{array}{c}\text { VLR } \\
\text { VSIILLE LUGT } \\
\text { REFLECTANCE }\end{array}$ & $\begin{array}{c}\text { VLRi } \\
\text { VISIBLELIGHT } \\
\text { REFLECTANCE }\end{array}$ \\
\hline COLOUR AND TYPE & \% & EXTERNAL\% & INTERNAL \% \\
\hline $5 \mathrm{~mm}$ Bronze (VFloat"m) & 54 & 6 & 6 \\
\hline $6 \mathrm{~mm}$ Bronze (VFloot" & 51 & 5 & 5 \\
\hline $10 \mathrm{~mm}$ Bronze (VFloat"m) & 34 & 5 & 5 \\
\hline $5 \mathrm{~mm}$ Dark Grey & 22 & 4 & 4 \\
\hline 6mm Dark Grey & 15 & 4 & 4 \\
\hline Smm Green (Guardian ME) & 79 & 8 & 8 \\
\hline Gmm Green (Panasap) & 70 & 6 & 6 \\
\hline $10 \mathrm{~mm}$ Green (Guardian ME) & 68 & 7 & 7 \\
\hline $4 \mathrm{~mm}$ Grey (Euro) & 56 & 6 & 6 \\
\hline $5 \mathrm{~mm}$ Grey (Euro) & so & 5 & 5 \\
\hline $6 \mathrm{~mm}$ Grey (Euro) & 44 & $\mathbf{5}$ & 5 \\
\hline $8 \mathrm{~mm}$ Grey (Euro) & 34 & 5 & 5 \\
\hline $10 \mathrm{~mm}$ Grey (Euro) & 26 & 4 & 4 \\
\hline $12 \mathrm{~mm}$ Grey (Euro) & 20 & 4 & 4 \\
\hline $6 \mathrm{~mm}$ Dark Blue & 58 & 6 & 6 \\
\hline $6 \mathrm{~mm}$ Super Blue & 53 & 6 & 6 \\
\hline $6 \mathrm{~mm}$ Super Green & 67 & 6 & 6 \\
\hline $6 \mathrm{~mm}$ Super Grey & 9 & 4 & 4 \\
\hline
\end{tabular}

Fig 3. Data of tinted glasses and their transmission percentage level (8)

From the data given above in the picture, we can infer that each type of tinted glass has each property such as visible light transmission (amount of visible light the glass transmits), internal (the ability of the glass to trap the light from escaping back to the atmosphere) \& external reflection. Hence, the tinted glass in this setup can be used according to the comforts of the person inside the room. E.g., if there's too much light coursing into the room, there is a need for diminishing the intensity, at that time, a glass with less visible transmission (Grey tinted glasses) is used.

\section{Colour filter:}

A sticker or thin glass having different sensitive layers which are coloured is a colour filter. They have a wide range of applications. But in this conceptual setup, these filters are used to change the colour of the light to achieve mood lighting. 
The below picture explains the physics behind the working of a colour filter. It is familiar that white light(sunlight) is a mixture of RGB (red, green, blue) colours predominantly, and when passed through a red filter will selectively absorb the blue and green colours and let only red pass through it, and this is similar for rest of the filters too.
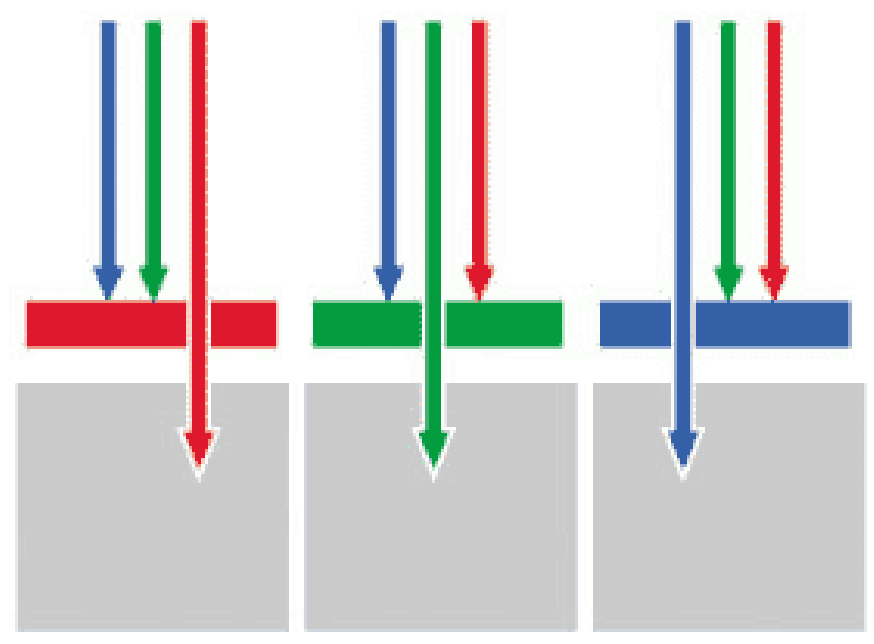

Fig 4. Working of the colour filter (9)

Motor:

A DC motor is used for controlling the intensity of the light and also helps in introducing the colour filters inside the tube so that it changes the colour of the light coming inside the room. DC motors are just like any other class of motors, which convert electrical energy into mechanical energy. A remote controller is used for operating the motors. In this concept, a DC brush motor of capacity $12 \mathrm{~V}, 10-20 \mathrm{Nm}, 60-100 \mathrm{rpm}$, unload current: $3 \mathrm{~A}$, rated current: $4.5 \mathrm{~A}$, (just like a motor used by automotive manufacturers for power window purpose, seats, which are operated by buttons) is used, because of its simplicity and affordability (10). As stated above just like power window are powered by the battery of a car, the motor used in this setup is connected to a battery which is powered by solar panels.

\section{Diffuser:}

A device that is used for scattering the sunlight into the room. Usually, light can be scattered by frosted glass, but glasses have a high absorption coefficient. There are innumerable applications of light diffusers such as in-camera, photography etc. But the use of a diffuser in the concept proposed in the paper is to scatter the light which is coursing in through the mirror tube, throughout the room. Either polycarbonate or acrylic diffusers are preferred due to their optical properties mainly it has the highest level of illuminance. Polycarbonate edges over other material also due to its soft transmission of light, which is one of the main objectives in the proposed concept.

\section{An opaque sheet:}

In case of rain or bad weather, the opening of the tube is covered with this sheet to avoid leakage through it. This sheet is controlled with a motor too. This material should be thick, air-tightly fit with the mirror tube and should be hydrophobic (so that, during rain the material does not absorb any water).

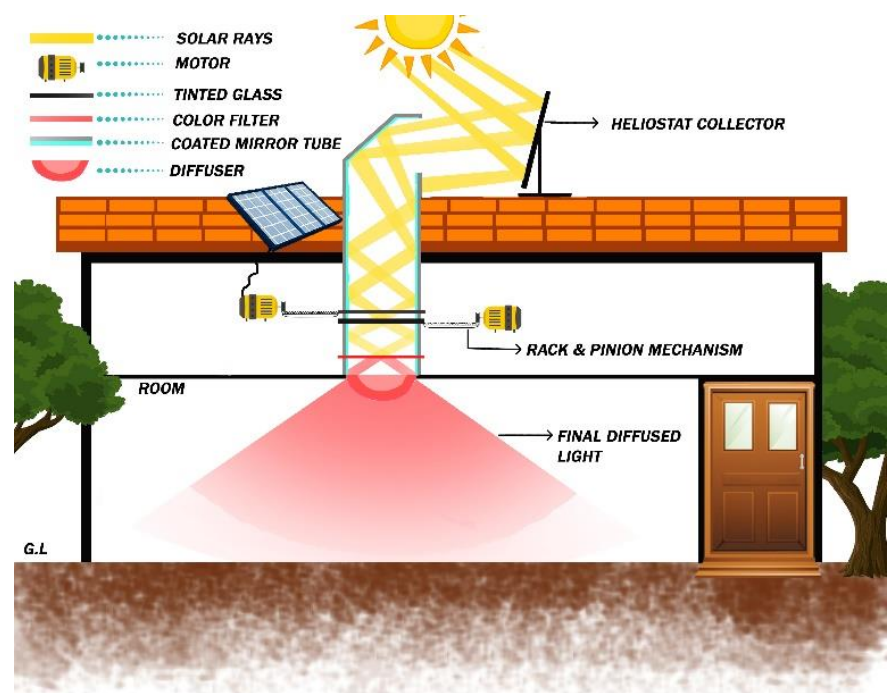

Fig 5. Conceptual setup of the transmission system

\section{WORKING}

Direct solar light falling on the roof of a building is collected via a tracking heliostat collector. The heliostat is an additional setup with a solar tracker so that it could collect the solar light throughout the day, and s also set in such a way that the sun's rays are falling on the heliostat's surface are always perpendicular (e.g., in India the Sun moves from east to west via the south, thus in this situation, placing the heliostat such a way that it faces south would be the evident option).

Then the collected light is reflected into the mirror tube through which the solar light is transmitted into the room.

As the light courses into the room, if the intensity of the light is immense (especially during afternoon-evening) and is felt uncomfortable by the person, there is a technology introduced for this issue. Tinted glasses of varying percentages can be introduced in between the mirror tube so that it blocks some of the light-transmitting through it.

In the proposed intensity varying system these are the components used

- Motors

- Tinted glasses

- Spring attached to a stationary object(wall).

When there is no need to reduce the intensity of light, the edge of the tinted glass which is cut into the same radius of the mirror tube and which is also coated with protected silver/ gold covers the left slit such that there is no gap and the normal transmission process occurs. And the right slit is closed by arc closer which is also coated by protected silver/ gold. The arc closer is supported by a spring to ensure that the closer closes the slit without any gap (i.e., the spring is in an expanded form).

When there is a need to control the intensity of light coursing into the room, the motor (which is powered using energy obtained from solar using solar panels) is operated using a controller and with the help of a simple rack and pinion mechanism, the rotational motion is converted to linear motion 
and the tinted glass is pushed into the slit present in the mirror tube and the arc closer is opened up as the spring is compressed due to the glass pushing it, and the glass is inserted incompletely. Then the light is coursed into the room with reduced intensity.

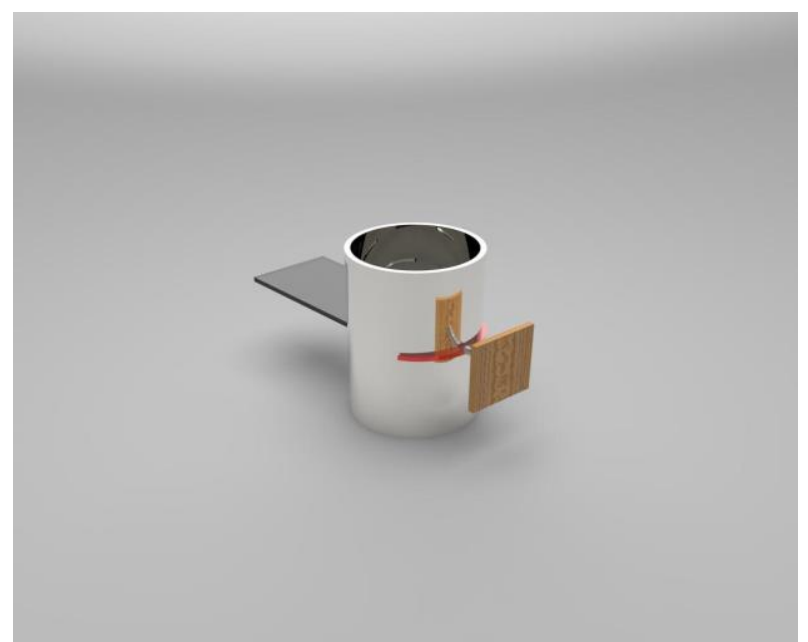

Fig 6. The mechanism used for glass/colour filter introduction

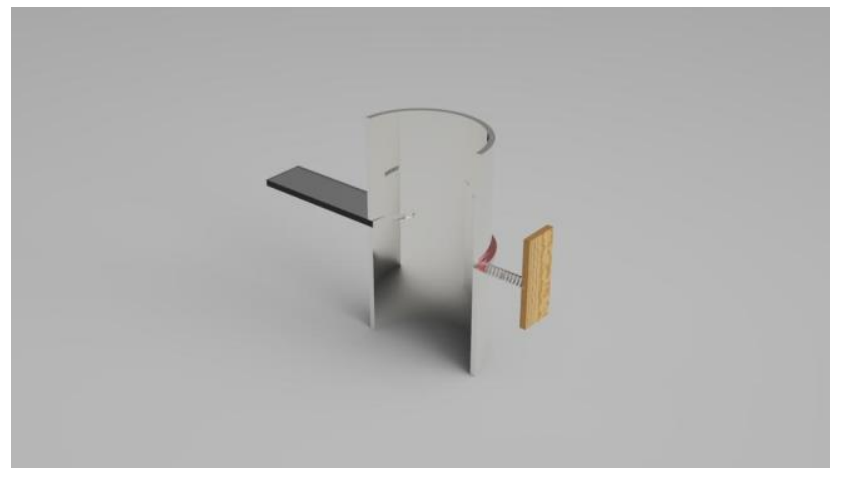

Fig 7. Sectional view when the mirror tube is closed completely

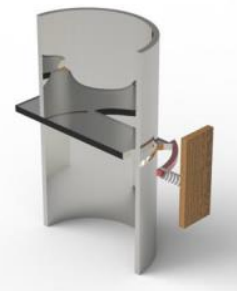

Fig 8. Sectional view when the tinted glass is introduced

Now considering the colour changing concept, the abovementioned same mechanism is used except that instead of tinted glasses, colour filters are used. There can be losses while the light is passing through the filters, as some photons are absorbed (since the filter absorbs certain wavelengths and transmit the other wavelengths). Therefore, there might not be a distinct change in colour but there will be a slight(pleasant) change in the colour of the light which is the main goal of the concept, mood lighting.

The mood lighting concept depends on both intensity and the colour of the light, therefore both the factors can be adjusted according to the person inside the room easily with the help of a controller/remote.

The proposed setup contains a total of 3 slots for tinted glasses as well as for colour filters, which can be used in the following possible ways.

- 2 tinted glasses of different light transmitting percentage levels and a colour filter.

- 2 colour filters of different colours and tinted glass for intensity control.

- 3 colour filters in all 3 slots.

- 3 tinted glasses of different light transmitting percentage levels in all 3 slots.

The final light to be achieved inside the room is controlled accordingly and is diffused throughout the room with the help of a diffuser.

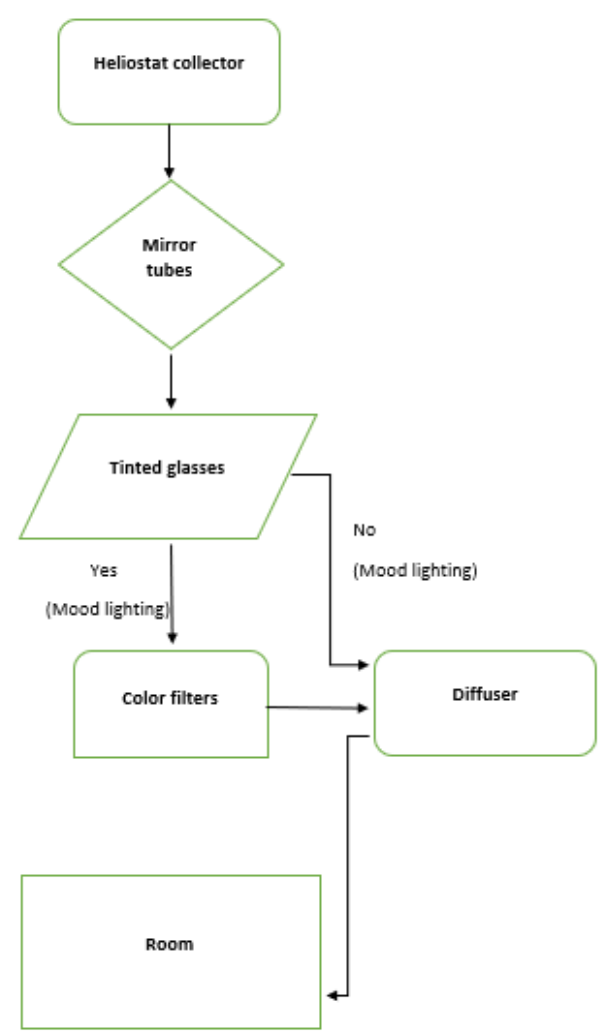

Fig 9. Flow diagram of the proposed Light transmission system

\section{DISCUSSION:}

The use of solar tube lighting has many merits and demerits of its own.

Usually, the sun's rays contain many sources of vitamins especially Vitamin D and also exposure to it has many health benefits, but constant exposure to sunlight may lead to many skin related problems. 
International Journal of Engineering Applied Sciences and Technology, 2021

Vol. 6, Issue 1, ISSN No. 2455-2143, Pages 420-424

Published Online May 2021 in IJEAST (http://www.ijeast.com)

The solar tube lighting setup has a design that is very flexible so that we can use it according to the architecture of the building, but the number of design variations available is very few. But, the installation of a solar tube lighting setup is limited to a certain angle of the steepness of the roof (11).

The opaque sheet provided on the top of the setup is used to block unwanted dust or rainwater to enter. the sheet is connected with a motor so that one can operate it from their home itself through remote control.

Isopropyl alcohol or acetone can only be used to clean the protected metal coated mirrors. Also, silver-coated mirrors require additional care due to their susceptibility to damage from environmental conditions and improper handling. Moreover, the Scratch-dig of the mirror should be of standard quality. Where scratch is any making or tearing of the part surface and dig in the small rough spot or pit in the surface.

As the proposed setup uses natural sunlight as its only source of lighting the emissions and power consumption is NIL. The setup depends only upon sunlight for the lighting, but it would be a demerit at the time of rains or a no sun day (11). Also, the setup can only be used in rooms that are quite nearer to the terrace.

\section{CONCLUSION}

The main concern of present-day life is the use of eco-friendly and non-conventional sources of energy in place of electricity. But when it comes to a country like India, we are still way behind in these applications, so this project has been developed to reduce the maximum part of power(electricity) consumption in daily life i.e., for lighting. This model has been meant to be constructed in such a way that there will be no use of electricity and the only primary source of lighting is natural sunlight. The proposed paper incorporates the concept of mood lighting with daylighting. The paper talks about the working, construction, advantages and disadvantages of the system. This reduces the burden of dependence on electricity and acts as a step of the move towards green electricity.

\section{ACKNOWLEDGMENT}

We are thankful to M.Madhumitha, (Architect \& IGBC AP) for her support in concept development and encouragement in this research project.

\section{REFERENCE}

[1] Daylighting, Article in Optics and Photonics News

[2] https://hmcarchitects.com/news/passive-daylightingsystems-could-transform-the-architecture-of-natural-light2019-05-24/

[3] https://en.wikipedia.org/wiki/Daylighting

[4] https://socketstore.co.uk/help/lighting/what-is-moodlighting/\#

[5] https://londonimageinstitute.com/how-to-empoweryourself-with-color-psychology/

[6] https://helioscsp.com/the-science-behind-heliostats-andconcentrated-solar-power-csp-heliostats/

[7] https://www.edmundoptics.com/knowledgecenter/application-notes/optics/metallic-mirror-coatings/
[8] https://www.nationalglass.com.au/wpcontent/uploads/2016/08/Tinted-Glass_v5-Low-Res.pdf [9] https://king-samuel.wixsite.com/ks3-science/colour

[10] https://www.researchgate.net/figure/2-Specifications-ofPower-Window-Motor_tbl5_236583956

[11]https://www.solarpowerfam.com/advantages-anddrawbacks-to-solar-tube-lighting/ 